\title{
Fire behavior of axially loaded slender high strength concrete-filled tubular columns
}

\author{
Manuel L. Romero ${ }^{\mathrm{a} *}$, V. Moliner ${ }^{\mathrm{b}}$, A. Espinos ${ }^{\mathrm{a}}, \mathrm{C}$. Ibañez ${ }^{\mathrm{a}}$ and A. Hospitaler ${ }^{\mathrm{a}}$ \\ ${ }^{a}$ Instituto de Ciencia y Tecnología del Hormigón (ICITECH). Universitat Politècnica de \\ València, Spain \\ ${ }^{\mathrm{b}}$ Centro Técnico del Fuego, AIDICO, Valencia, Spain
}

\begin{abstract}
This paper describes sixteen fire tests conducted on slender circular hollow section columns filled with normal and high strength concrete, subjected to concentric axial loads. The test parameters were the nominal strength of concrete (30 and $80 \mathrm{MPa}$ ), the infilling type (plain concrete, reinforced concrete and steel fiber reinforced concrete) and the axial load level (20\% and 40\%). The columns were tested under fixed-pinned boundary conditions and the relative slenderness at room temperature was higher than 0.5 in all of the cases. A numerical model was validated against the tests, in order to extend the results and understand the failure mode of such columns. It is the aim of this paper to study the influence in a fire situation of the use of high strength concrete, as opposed to normal strength concrete. The results have shown that for slender columns subjected to high temperatures, the behavior of high strength concrete was different than for stub columns, spalling not being observed in the experiments. Furthermore, the addition of steel fibers was not found very advantageous in slender columns, since no increment in terms of fire resistance was obtained for the columns which used this type of reinforcement. However, the addition of reinforcing bars seems to be the solution in some cases, where the use of external fire protection wants to be avoided in the design of HSS structures, since the reinforcing bars allow the tube to resist a higher axial load.
\end{abstract}

Keywords: fire resistance, composite column, concrete-filled tubular column, high strength concrete 
*Corresponding author: Tel: +34-963877007(ext: 76742) Fax: +34-963879679,

E-mail address: mromero@mes.upv.es

\section{NOTATION}

$\begin{array}{ll}\text { CFT } & \text { Concrete filled tube } \\ D & \text { Diameter of the column } \\ t & \text { Thickness of the steel tube } \\ \text { EC2 } & \text { Loading eccentricity } \\ \text { EC3 } & \text { Eurocode 2 Part 1-2 (EN 1992-1-2) } \\ \text { EC4 } & \text { Eurocode 3 Part 1-2 (EN 1993-1-2) } \\ \text { P-P } & \text { Eurocode 4 Part 1-2 (EN 1994-1-2) } \\ \text { F-P } & \text { Pinned-pinned supporting conditions } \\ \text { FCCR } & \text { Fixed-pinned supporting conditions } \\ \text { FEM } & \text { Fire concrete contribution ratio } \\ \text { FRR } & \text { Finite element modelling } \\ f_{c} & \text { Fire resistance rating } \\ f_{s} & \text { Compressive cylinder strength of concrete at room temperature (test date) } \\ f_{y} & \text { Yield strength of reinforcing steel at room temperature } \\ \text { HSC } & \text { Yield strength of structural steel at room temperature } \\ \text { NSC } & \text { High strength concrete } \\ \text { HSS } & \text { Normal strength concrete } \\ L & \text { Steel hollow section } \\ N & \text { Length of the column } \\ N_{R d} & \text { Test load } \\ T & \text { Resistance of the column in axial compression at room temperature } \\ \mu=N / N_{R d} & \text { Temperature } \\ \end{array}$

\section{INTRODUCTION}

Concrete filled tubular (CFT) columns combine the action of steel and concrete when carrying compression loads and moments showing an ideal structural performance. While the steel tube confines the concrete core enhancing its compressive strength, the concrete core 
prevents the steel section from experiencing local buckling. Due to that, the use of CFT columns has increased, becoming very popular in last years.

Furthermore, the fire resistance of CFT columns is higher than that of hollow steel tubular columns, external protection being not needed in most cases. When the steel tube is filled with concrete, while the steel section gradually loses its strength and stiffness the load is transferred to the concrete core, which due to its lower thermal conductivity heats up more slowly. During a fire, the steel tube acts as a radiation shield to the concrete core and a steam layer in the steel-concrete boundary appears. Both effects lead to a lower temperature rise in the cross-section as compared to empty steel tubes and exposed reinforced concrete structures [1]. Wang and Kodur [2] recommended the use of such typology of columns in order to avoid the use of external fire protection when designing steel structures.

The use of high strength concrete (HSC) as infilling in CFT columns is very popular amongst designers and has recently become a good alternative to normal strength concrete (NSC). At room temperature, high strength CFT columns show higher load-bearing capacity than those filled with traditional NSC. The benefits of using HSC are higher for non-slender columns or for columns with low D/t ratio, but, in general, the use of HSC filled tubular columns is highly interesting due to the enhancement of ductility as compared to that of common high strength reinforced concrete columns. Results from Portolés et al. [3] ,[4] show the utility of the concrete contribution ratio for different values of slenderness, concrete strength or confinement index.

At elevated temperatures, although it is known that HSC behaves in a different way that NSC, its performance is not completely defined. Lu et al [5], Ding and Wang [6] and Espinos et al. [7] developed numerical models and established that the behavior of axially loaded CFT columns under fire can be divided into different stages. 
In previous work [7], the authors of this paper presented the evolution of the column axial displacement along time through four stages. Due to its higher thermal conductivity and its direct exposure to fire, the steel tube heats up more rapidly and consequently expands faster than the concrete core. This difference in the axial displacement rate and the appearance of a gap at the steel-concrete interface lead to the subsequent loss of contact of the concrete core with the loading plate. Because of this fact, the axial load ratio of the steel tube gradually increases, up to a point where the whole applied load is sustained by the steel tube alone (stage 1), Figure 1. This situation remains until the steel tube reaches its critical temperature and the local yielding of the steel section occurs (stage 2). At this point, the steel tube starts to shorten, allowing the loading plate to contact back the concrete core. As the column shortens, the load sustained by the steel tube is progressively transferred to the concrete core (stage 3 ) and, as a consequence, the axial force ratio undergoes an inversion. In this stage, the concrete core is the element of the column showing more resistance, since the steel tube has lost its load-bearing capacity in the previous stages. As the temperature advances through the inner section, the concrete core mechanical properties are progressively degraded, and after a significant period of time the concrete core completely loses its strength and stiffness, leading to the ultimate failure (stage 4).

According to Kodur and Latour [8] and Ali et al [9], when high strength concrete filled columns are exposed to fire, one of the most important factors affecting their behavior is spalling, , as it leads to a explosive deterioration of the material due to the development of internal pore pressures.

Schaumann et al [10] detected spalling when performing a series of fire tests on high strength CFT columns filled with different types of concrete, and stated that its effects could be minorated by means of using steel bars or steel fiber reinforcement. Contrarily, Lu et al [5] , after testing a series of stub columns filled with high strength self-consolidating concrete, 
concluded that the fire behavior of these columns was found to be the same as that for normal strength CFT columns.

Thus, the possibility of this phenomenon to appear during a fire makes it necessary to evaluate the convenience of using HSC as infilling in hollow steel section columns, as their fire resistance could be affected.

While the fire behavior of normal strength CFT columns has been deeply investigated for years and numerous test programs have been carried out for both slender and non-slender columns (Lie and Chabot [11], Chabot and Lie[12] , Lie[13] , Kordina and Klingsch [14], Park et al [15] [16], Chung et al [17] and Han et al [18] ), no extensive experimental programs specifically designed for slender high strength CFT columns can be found in the literature. Only Hass et al. [20] , and Han et al. [21] have performed some tests combing HSC and slender concrete-filled columns.

Kodur et al [8] performed a series of fire tests on circular and square CFT columns of reduced slenderness filled with high strength concrete. The tested specimens were either unreinforced or reinforced with bars or steel fibres. In turn, Lu et al [5] carried out an experimental program consisting of 6 stub columns filled with self-consolidating HSC of grades ranging from 90 to $99 \mathrm{MPa}$. Nevertheless, the results from these authors do not provide enough information to evaluate the influence of the main factors affecting the fire behavior of high strength CFT columns.

In this paper, results from an experimental program for slender axially loaded CFT columns subjected to fire is presented. The infilling of these columns was of three different types: plain concrete, reinforced concrete and steel fiber reinforced concrete. The concrete strength was a parameter in this research, using concrete mixes of $30 \mathrm{MPa}$ (NSC) and $80 \mathrm{MPa}$ (HSC). By means of the results from the experimental program, the numerical model proposed by the authors in previous work [7] was validated. With the help of this model, a 
deeper study on the failure mechanism of such columns was performed, while a new parameter was proposed (the fire concrete contribution ratio, FCCR) which helps to quantify the importance of the use of concrete infilling in hollow steel section columns exposed to fire and allows to evaluate the interest of using high strength concrete compared with normal strength concrete.

\section{EXPERIMENTAL PROGRAM}

In this experimental program, sixteen fire tests were carried out on normal and high strength concrete-filled tubular columns. The aim of the program was to investigate the effects of three main parameters on the fire behavior of these columns: concrete strength $\left(f_{c}\right)$, type of concrete infilling (plain, reinforced and steel fiber reinforced) and the load level $(\mu)$. According to the common practice in construction, test values of these parameters were selected. All the tested columns were $3180 \mathrm{~mm}$ long and had a diameter of $159 \mathrm{~mm}$. Only a D/t ratio value was used, with a steel tube wall thickness of $6 \mathrm{~mm}$. Those values were chosen in order to obtain slender columns, avoiding local buckling. With regard to the concrete nominal strength, two values were used: 30 and $80 \mathrm{MPa}$. In all the tests, the load was axially applied and its value was calculated as a percentage of the corresponding ultimate load at room temperature, which was obtained by means of a validated numerical model developed by Lacuesta et al. [22] . Again, according to the common load levels found in practice, values of $20 \%$ and $40 \%$ were adopted, although in some cases the $60 \%$ was also adopted. In Table 1, data of the tested columns can be found.

All of the tests were performed in the testing facilities of AIDICO (Instituto Tecnológico de la Construcción) in Valencia, Spain. The tests specimens can be identified as follows:

NXXX-T-L-FF-EE-AA (i.e. C159-6-3-30-0-20), where $\mathrm{N}$ stands for the type of concrete $(\mathrm{C}=$ plain concrete, $\mathrm{RC}=$ reinforced concrete and $\mathrm{FC}=$ fiber reinforced concrete), $\mathrm{XXX}$ is the 
nominal diameter of the column in $\mathrm{mm}$, T represents the steel tube wall thickness in $\mathrm{mm}, \mathrm{L}$ the nominal length of the column in meters, FF the nominal concrete strength in MPa, EE the load eccentricity and AA the axial load level. In this paper, all the tests were conducted under axial compression and thus $\mathrm{EE}=0$ for all the cases. Nevertheless, this label will be maintained in this work, since the authors are currently performing more tests in a new experimental campaign subjected to eccentric loads.

\subsection{Steel}

Cold formed circular steel hollow sections were used in the experimental program. The steel grade was S275JR, nevertheless the real yield strength $\left(f_{\mathrm{y}}\right)$ of the empty tubes was obtained by performing the corresponding coupon tests, Table 1 . The mean value of the steel modulus of elasticity Es was $210 \mathrm{GPa}$ according to European standards.

\section{2.- Concrete}

As mentioned above, the experimental program involved concrete mixtures of normal (30 $\mathrm{MPa})$ and high strength concrete $(80 \mathrm{MPa})$ both for plain and steel fiber reinforced concretes, the type of aggregates being calcareous in all cases.

In order to determine the compressive strength of concrete, sets of concrete cylinders were also prepared and cured in standard conditions during 28 days. All cylinder samples were tested on the same day that the column was tested. The cylinder compressive strength of concrete in all the tested specimens can be found in Table 1.

In order to measure the humidity of concrete, cubic specimens $(150 \times 150 \times 150 \mathrm{~mm})$ were also prepared. After 28 days, the weight of each sample was measured before and after drying them in a small oven at $150^{\circ} \mathrm{C}$ and the moisture level was obtained accordingly. 


\section{3.- Specimens}

The length of the columns was $3180 \mathrm{~mm}$, although only $3000 \mathrm{~mm}$ were exposed to fire inside the furnace. Two ventilation holes of $15 \mathrm{~mm}$ diameter were drilled and located at 100 mm from each column end, as proposed by Lie and Chabot [11]. All the columns had a relative slenderness at room temperature higher than 0.5 , Table 1.

The relative slenderness of a composite column $\bar{\lambda}$ is defined in Eurocode 4 Part 1-1 as:

$$
\bar{\lambda}=\sqrt{\frac{N_{p l}}{N_{c r}}}=\sqrt{\frac{A_{c} f_{c}+A_{s} f_{y}}{\frac{\pi^{2} E I}{L^{2}}}}
$$

where $E I=E_{s} I_{s}+0.6 E_{c m} \cdot I_{c} ; I_{s}$ and $I_{c}$ are the second moment of inertia of the steel tube and the concrete core respectively; $E_{\mathrm{s}}$ is the modulus of elasticity of steel; and $E_{\mathrm{cm}}$ is the secant modulus of elasticity of concrete.

In order to facilitate the pouring of fresh concrete, a 300x300x $15 \mathrm{~mm}$ steel plate was welded to the bottom of each empty steel tube.

In order to register the temperature evolution during the fire test, a set of five thermocouples were positioned in the mid-length section following Fig. 2a. While thermocouple number 1 was welded to the steel tube surface, the other 4 thermocouples were embedded in the concrete core. Thermocouple number 2 was placed at $1 / 6$ of the section width, number 3 at $1 / 3$, number 4 at the center of the section and number 5 was positioned at $1 / 4$ of the section width.

Concrete was poured with the column placed in vertical position and afterwards shaken with a needle vibrator. Once the casting was finished, the specimens were covered with a wet cloth and a plastic film during 1 week. Later on, a second steel plate was welded to the top end of the column. 
The tests of the bar reinforced specimens (RC) followed the arrangement of Fig 2.b, where four longitudinal reinforcing bars of $12 \mathrm{~mm}$ diameter were added and $6 \mathrm{~mm}$ stirrups located every $30 \mathrm{~cm}$ along the column length. The geometrical reinforcement ratio was close to $2.5 \%$.

The tests of the steel fiber reinforced specimens (FC) had the same concrete mix than the PC filled, but with an addition of $40 \mathrm{Kg} / \mathrm{m} 3$ high strength Dramix 40/60 steel fibers.

\section{4.- Test set up and procedure}

The tests were carried out in a $5 \times 3 \mathrm{~m}$ furnace equipped with a hydraulic jack of $1000 \mathrm{kN}$ maximum capacity, Figure 2.c. There were 16 gas burners in the furnace chamber, arranged in two horizontal rows containing 8 burners each, located at mid-height of the chamber. The columns were placed vertically inside the furnace, fixed (F) at the bottom end and pinned (P) at the top end, Figure 2.e.

In order to investigate the effect of the applied load over the steel-concrete interface thermal resistance and thus over the cross-sectional temperature distribution, an unloaded stub column of $1 \mathrm{~m}$ length was also located inside the furnace chamber and the temperatures registered by means of one thermocouple welded to the steel surface and a second thermocouple placed in the concrete outer layer, Figure 2.d. In the first tests, five thermocouples had been introduced in both unloaded and loaded columns, but as the interest was to study the thermal resistance at the steel-concrete interface, thermocouples T3 to T5 were removed from the stub columns.

Once the load was applied, it was kept constant and the burners were then activated, Figure 2.f, following an ISO-834 fire curve [19] with unrestrained column elongation. The temperature inside the furnace was automatically controlled by 5 thermocouples and pressure sensors located inside the furnace chamber. The axial elongation of the columns was measured by LVDTs located outside the furnace. 
An additional pinned-pinned slender column (case 2) was tested in order to measure the influence of the slenderness of the column by changing its boundary conditions. Furthermore, an empty column (case 1) was initially tested in order to obtain a magnitude of the fire resistance of the hollow steel tube.

\section{TESTS RESULTS}

\subsection{Axial elongation versus time.}

Figure 3 presents the axial elongation (y-axis) versus time (x-axis) curve registered during the fire test, and the corresponding Table 1 presents the resulting FRR (fire resistance rating), obtained according to EN 1363-1. In general, it can be seen that for slender columns only a short fire resistance period can be obtained, particularly in those cases subjected to high axial load levels ( $\mu=0.4$ or $\mu=0.6$ ), where the FRR was lower than 30 min. Nevertheless, those cases with a small axial load level $(\mu=0.2)$ presented FRR values over $30 \mathrm{~min}$.

As expected, from Figure 3a it can be inferred that for both normal and high strength concrete, the higher the axial load level is, the lower the fire resistance results.

From Figure 3a and Table 1, the FRR of the cases filled with plain concrete can be compared. It can be observed that the fire resistance was lower for the HSC specimens, although it is important to clarify that this cases were subjected to a higher axial load in terms of absolute values, for a same relative axial load level. Furthermore, it can be observed in Figure 3.a that the case with $\mathrm{fc}=80 \mathrm{MPa}$ and $\mu=0.4$ had a different behaviour, where stage 3 from Figure 1 (contribution of the concrete core) did not appear completely. In these cases the failure was due to the overall buckling of the steel tube when trying to transfer the load to the concrete core. In such situation, the presence of concrete in comparison with an empty hollow section only affects the temperature distribution and not the mechanical resistance during the fire tests. No sudden deterioration of the material was observed in the HSC specimens, what 
suggests that spalling is not present in slender CFT columns. The existence of spalling is very difficult to demonstrate or neglect in concrete-filled columns, in fact some specimens were cut and the steel tube wall removed so as to observe the concrete infill, Figure 2.g, noticing no evidence of any kind of spalling.

In general, the same conclusions can be obtained from Figure $3 \mathrm{~b}$ and $\mathrm{c}$ for the cases of barreinforced concrete (RC) and steel fiber reinforced concrete (FC).

For the cases filled with bar-reinforced concrete, the FRR was slightly higher than that of the cases filled with plain concrete, finding particularly surprising that case with $80 \mathrm{MPa}$ concrete strength and $\mu=0.2(65 \mathrm{~min})$. Furthermore, the bar-reinforced columns were subjected to a higher axial load than the plain concrete filled columns: a $15 \%$ increase for NSC and a $5 \%$ increase for HSC.

However, the cases filled with steel fiber reinforced concrete (FC) combined with normal strength concrete (NSC) did not see their FRR improved: see cases 3 and 4 versus 13 and 14. In these columns, the same axial load was applied to the plain concrete and steel fiber concrete filled specimens.

Up to now, the authors have not found a unique explanation to this phenomenon. In some cases, a difference can be found in the evolution of temperatures from the thermocouples (not shown in this paper for simplicity), where the FC cases presented higher temperatures in the concrete, but for other tests it cannot be fully demonstrated.

Nevertheless, for the steel fiber reinforced HSC specimens, the FRR was only improved in the case with higher axial load level and thus higher influence of the second order effects (case 7 versus 16), which can be due to the brittle nature of such concrete, the addition of fibers being more useful here to increase the tensile strength.

While Kodur and Latour [8] reported that steel fibers can be used to increase the fire resistance of high strength concrete filled steel columns, the test results given in this paper do 
not support this statement. The main difference between both experimental campaigns is that the columns presented here had a high slenderness, over 0.5 . In these cases the steel fibers do not contribute to the fire resistance of the column since the failure is mainly due to the hollow steel column premature buckling.

This behaviour can be compared in Figure 4a, where the effect of the type of infilling for the HSC specimens with $\mu=0.4$ is compared. It is worth noting that the FRR values are very small (between 0 and $25 \mathrm{~min}$ ) in these three cases, what prevents the authors to achieve a solid conclusion this time.

It is also interesting to compare the pinned-pinned (P-P) case with the fixed-pinned (F-P) case with $\mu=0.4$ in order to reach an initial conclusion about the influence of the slenderness, Figure $4 \mathrm{~b}$. It is clear that for the pinned-pinned case, stage 3 does not appear and the steel tube fails before transferring the load to the concrete core, while in the fixed-pinned case this load transfer occurs. The main explanation to this fact is that if second order effects produced by the curvature in the steel tube are very large, they cannot be transferred to a fragile material as unreinforced concrete and thus the presence of concrete does not result effective in very slender hollow section columns.

\section{2.- Temperature.}

As it was mentioned in the previous section, an additional unloaded stub column of the same cross-sectional geometry and materials was introduced in the furnace chamber close to the slender column, Figure 2.d, in order to compare the difference in the cross-sectional temperature distribution, Figure 2.a.

Figure 5 presents a comparison of temperatures T1 and T2 between the slender column and the stub column, while the rest of the temperatures (T3 to T5) are not included in the graph for simplicity. 
It can be concluded that there is not a big difference between the thermocouples inside the concrete (T2 to T5) while there is a big difference between the thermocouples that are in the surface of the steel (T1). After a deep analysis of this behavior the only explanation found is that there was a big influence of the location of the thermocouples relative to the burners over the measurements and thus thermocouple $\mathrm{T} 1$ in the slender column was not measuring exactly the temperature of the steel because the flame was affecting this measurement. This issue was confirmed in complementary experiments carried out in the laboratory by placing a new $\mathrm{T} 1$ thermocouple in the steel surface of the slender column now at L/4 from the bottom end instead of in the mid-length of the column. In this case, the $\mathrm{T} 1$ long measurement was found to be similar to the $\mathrm{T} 1_{\text {stub }}$ measurement.

This leads the authors to the conclusion that the existence of load and second order effects does not affect significantly the thermal resistance at the steel-concrete interface and thus has not a big influence in the temperature distribution across the section. This allows, when carrying out numerical simulations, to first perform a pure heat transfer analysis to obtain the cross-sectional temperature field without accounting for the effects of the load and afterwards to apply the resulting temperature distribution to the mechanical model; that is, to perform a so-called sequentially-coupled thermal-stress analysis instead of a fully-coupled analysis, neglecting the possible effect of the displacements over the temperature evolution.

\section{COMPARISON WITH EUROCODE 4}

In this section, the experimental tests are used to study and discuss the EC4 simple calculation model provisions [24]. This standard provides a simple method for calculating the fire resistance of CFT columns subjected to concentric axial loads. The current field of application of EC4 simple calculation model is C20/25-C50/60, so only columns with concrete cylinder 
strength under $50 \mathrm{MPa}$ can be calculated, nevertheless the application of the method for HSC will be intended here in order to check its validity in this range of concrete strengths.

Recently, Aribert et al. [22] have highlighted several shortcomings of EN 1994-1-2 [24]

Annex $\mathrm{H}$, which at present is under revision. While a new specific simplified model for concrete filled columns in fire is developed, it seems that following the general principles of Clause 4.3.5.1 is more appropriate. However, as the values of the reduction coefficients to account for the effect of thermal stresses are not given in EN 1994-1-2[24] for concrete filled columns, some assumptions must be adopted for their treatment. In the absence of predefined values, a common approach in practice is to take them as equal to unity. More details on the discussion of the method can be found in [25] .

\section{a) Temperature field}

It is known that the EC4 simple calculation model requires the cross-sectional temperature field to be previously known and applied as a first step for obtaining the fire resistance of unprotected concrete filled hollow section columns in axial compression. Therefore, the calculated axial buckling load in fire will be influenced by the level of accuracy of the thermal distribution employed by the designer. In this paper the measured temperature field in the five thermocouples is used.

\section{b) Buckling resistance in Fire}

The pinned-fixed specimens from the tests were compared with the predictions of the EC4 simple calculation model. The buckling resistance of the columns at the time of test failure was obtained, and summarized in Table 2. It was found that in general the EC4 simple calculation model produced unsafe results when using flexural stiffness reduction coefficients equal to unity, but any reliable trend can be achieved without performing a parametric study, which is not the object of this paper. 
As can be seen in Table 2, the mean value was 0.85 for NSC and 0.89 for HSC respectively, the standard deviation being 0.20 and 0.17 , which demonstrates that the code does not produce accurate results for slender columns.

In general, it can be concluded that for centrally loaded columns, values of the relative slenderness at ambient temperature greater than 0.5 lead to unsafe results in the predictions of Clause 4.3.5.1 in EC4 unless a set of flexural stiffness reduction coefficients lower than unity are given. This fact was already confirmed by Aribert et al. [22] and Espinos et al [7] [25] , who found that EC4 simple calculation model leads to buckling load values which result unsafe for high column slenderness.

\section{c) Critical Temperature.}

The method of the critical temperature is defined in the Eurocode 3 and Eurocode 4 (for composite beams) [24] for a given load level as the temperature at which failure is expected to occur in a structural steel element for an uniform temperature distribution.

Lu et al. [5] stated that the limiting temperature achieved in the steel for CFT stub columns was independent of the type of concrete used and the failure modes of the columns.

However, if the temperature in the steel tube is measured at the time that the column fails in the fire test, an experimental value of the critical temperature (Tcr) can be obtained, which is presented in Table 4. This temperature is also compared with the value obtained by means of the method from the Eurocode 3 (EC3), which depends on the axial load ratio $(\mu)$ :

$$
T_{c r}=39,19 \ln \left[\frac{1}{0,9674 \mu^{3,833}}-1\right]+482
$$

Three values were obtained with this method of the critical temperature corresponding to: the nominal axial load ratio (nom), the real axial load ratio (with the measured values of fy and fc) and the axial load ratio of the steel tube alone (hollow). This last value was obtained 
because in some cases the failure is produced previously to load transfer between the steel tube and the concrete core.

From Table 3 it can be inferred that the statement from $\mathrm{Lu}$ et al [5] is not fulfilled in slender columns, where in most cases the critical temperature reached is higher than the corresponding for a hollow steel tube, which is due to the contribution of concrete in stage 3 to sustain the load while delaying the heating up of the steel tube.

There are some special cases (higher axial load ratio and/or high strength concrete) where the critical temperature reached in the test is even lower than the one obtained for the steel tube alone according to EC3. A parametric study is required to achieve solid conclusions.

\section{NUMERICAL MODEL}

Previous research on the modeling of the behaviour of concrete filled circular hollow section columns at room temperature and exposed to fire has been carried out by the authors [7] , where an advanced thermo-mechanical numerical model was developed and validated by comparing its results with a series of fire tests available in the literature [11] - [12] , [14] . By means of the finite element analysis package ABAQUS [27] , a three-dimensional numerical model for simulating the fire behaviour of CFCHS columns under axial compression was developed. An extensive sensitivity analysis was carried out, in order to investigate the main aspects of the model, which served as a basis for future work on the numerical simulation of CFT columns at elevated temperatures. Nevertheless, the validity of this model was limited to normal strength concrete.

From this basis, the second aim of the present paper is to validate the existing model with these experiments carried out by the authors, in order to extend its usage to a wider range of columns including those filled with HSC, so as to be able to understand the failure mode of 
such columns and evaluate their effectiveness in a fire situation when compared with normal strength concrete.

\section{1.- Validation.}

For each of the columns listed in Table 1, the axial displacement at the top of the column versus the fire exposure time was registered during the simulation, comparing this curve with the one obtained in the fire test. This figures have not been presented here for simplicity.

From the axial displacement versus time curves, the fire resistance rating was obtained for each one of the specimens under study. The values of the error are summarized for NSC and HSC in Table 2, presenting accurate results in terms of the mean value for both concrete types, although with more scarce results for HSC. As it can be seen, for NSC most of the values calculated lie in the region of the $15 \%$ error, which does not occur in some of the HSC results.

It can be noticed that there was more agreement with the test results in those columns subjected to lower load levels, whereas those columns subjected to higher loads and thus higher second order effects $(\mu=0.6)$ produced more error, which may be attributed to the higher contribution of concrete and its more complex failure mechanisms.

\section{High strength concrete}

The series of columns filled with high strength concrete must be studied with special care, since they are more likely to experience spalling when subjected to elevated temperatures. The values of their measured and computed fire resistance ratings are summarized in Table 2. Contrarily to what it was expected, the spalling did not appear and the comparison with the numerical simulations presented a similar trend than that for normal strength concretes. Anyway the standard deviation is higher and the particular results for $\mu=0.4$ suggests that a 
different failure mechanism is likely to be occurring at those column tests with higher concrete strength fillings.

\section{FAILURE MECHANISM}

Once the numerical model was validated, case 3 from Table 1 (normal strength plain concrete with $\mu=0.2)$ and case 10 ( $\mu=0.6$ with reinforced concrete) were studied in depth in order to understand their failure mechanism. The upper part (a) of figures 6 and 7 show the axial displacement-time curve together with the axial force ratio versus time curves for both the steel tube and concrete core.

The lower part (b) of figures 6 and 7 shows the distribution of normalized stresses in the steel tube and different points within the concrete core, together with the maximum stress that steel and concrete can reach, which varies along the fire exposure time.

In these graphs:

- "Smises" is the equivalent stress at a point of the steel tube according to Von Mises criterion

- $\quad$ "S33_concrete" is the normal stress at a point of the concrete core in the longitudinal direction of the column, see Figure $12 b$.

- "fy" is the yield strength of steel at room temperature

- $\quad$ "fc" is the compressive strength of concrete at room temperature

- $\quad$ "fyT" is the yield strength of steel at elevated temperature, from Eurocode 4-1-2.

- "fcT" is the compressive strength of concrete at elevated temperature, from Eurocode 4-1-2.

"fccT" is the compressive strength of concrete at elevated temperature accounting for the confinement effect, produced by the lateral pressure of the steel tube due to the ovalization of the section. 
- $\quad$ Fs (failure of steel) is the point where the failure of the steel tube occurs

- $\quad$ Fc (failure of concrete) is the point where the failure of the concrete core occurs

During the first minutes of heating, the steel tube heats up more rapidly and expands faster than concrete core, since it is directly exposed to fire and has a higher thermal conductivity. Because of this faster axial elongation of the steel tube and the occurrence of slip at the steelconcrete interface, the concrete core loses contact with the loading device, thus progressively increasing the axial load ratio of steel (A) until the whole applied load is sustained by the steel tube (B). The steel tube remains fully loaded during a significant period of time until the critical temperature of steel is reached. At this point, the local yielding of the steel tube occurs and it starts to shorten, allowing the loading device to contact the concrete core again. From Figure $6 \mathrm{~b}$ it can be seen that this point corresponds in time with the intersection between the misses stress at the steel tube (Smisses/fy) and the yield strength of steel at elevated temperature (fyT/fy), both normalized with the yield strength of steel at room temperature, point "Fs".

As the column shortens, the steel tube progressively transfers the load to the concrete core (C).

It is worthwhile noting that the total failure will occur when the first point of the concrete will fail too.

It is important to observe the longitudinal stress (S33) of three points inside the concrete, where " 1 " is the closest to the steel, and thus the most compressed and heated. Points "2" and " 3 " are under tensile stresses due to thermal effects.

The cross-sectional temperature gradient within the concrete core gives rise to a field of self-balanced thermal stresses, which are compressive in the outer layers of concrete and tensile in the central part of the concrete. The stresses in the central layers of the concrete core remain positive and increasing with temperature until the applied load is transferred from the 
steel tube to the concrete core, when the stresses in that central part of the concrete undergo an inversion, changing from tension to compression.

At the point "Fs" in Figure 6b, the compression stress at concrete point 1 increases, due to the inversion in the distribution of load between the steel tube and the concrete core, at the same time that its resistance is continuously being degraded due to the temperature, fcT.

The compressive strength of concrete at elevated temperature (fcT) given by Eurocode 4 has to be increased in order to take into account the confinement effects. An ovalization of the section was observed, producing a lateral pressure (S22) in the concrete core. So, the appropriate curve against which to compare is the "confined" compressive strength of concrete at elevated temperature (fccT1/fc), which can be estimated through the following expression:

$$
\mathrm{f}_{\mathrm{ccT}}=\mathrm{f}_{\mathrm{cT}}+4.1 \mathrm{xf}_{\text {lat }}
$$

updating the equation from Richart to high temperatures. The lateral pressure $\left(f_{\text {lat }}\right)$ is obtained from the numerical model.

It can be noticed in point " $\mathrm{Fc}$ " from Figure $6 \mathrm{~b}$ that the failure of the entire column appears when the curve "fccT1/fc" intersects with curve "S33_concrete_1/fc", point where both the steel and the outer layers of concrete are at the maximum capacity that their temperature allows.

However, especial mention should be made to the case with the higher axial load applied for normal strength concrete $(\mathrm{N}=687 \mathrm{kN})$, which is presented in Figure 7.

This case behaves in a different manner, because the hollow steel tube is loaded near its maximum capacity at room temperature and cannot sustain the load alone when the temperature is increased, needing the contribution of the concrete core all along the fire history. In this column, the redistribution of stresses between the steel and the concrete at elevated temperature is self-balanced producing that the failure occurs at the same time in the 
concrete and the steel, and the points "Fc" (failure of concrete) and "Fs" (failure of steel) appear at the same time. This aggregated behavior is positive because the hollow steel column does not work alone in any instant of the fire.

Furthermore, in this case the concrete has the additional contribution of the reinforcing bars, which do not produce a significant advantage here, due to the null or reduced eccentricity (only second order) and because of the fact that their location is very close of the center of gravity of the section, given the small diameter of the column.

In summary, it seems that it is important to secure a smaller ratio between the applied axial load and the hollow steel tube capacity to allow for the transference of load between the steel tube and concrete core and thus taking advantage of the contribution of concrete in the increment of the fire resistance time. Nevertheless, a parametric study will be necessary to be able to draw more sound conclusions.

\section{FIRE CONCRETE CONTRIBUTION RATIO (FCCR)}

A second objective of this paper was to establish the importance of filling with concrete the hollow steel section columns exposed to fire and also to study the interest of using high strength concrete compared to normal strength concrete. To do so, the fire concrete contribution ratio (FCCR) is defined as the ratio between the fire resistance rating of the

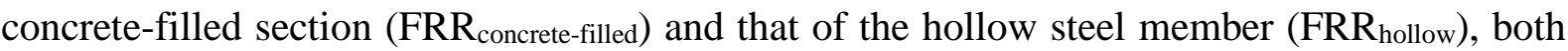
subjected to the same axial load:

$$
F C C R=\frac{F R R_{\text {concrete-filled }}}{F R R_{\text {hollow }}}
$$

The numerator can be obtained both experimentally or numerically, but the denominator can only obtained numerically, so to be consistent it was decided to obtain both of them numerically once the FEA model was validated. 
Table 4 presents the fire concrete contribution ratio (FCCR) obtained for the series of tested columns, which represents the gain which could be obtained in the fire resistance period by using concrete-filled columns rather than unfilled hollow steel columns. From this table it can be inferred that the fire resistance of a hollow steel section column can be increased at least two or three times, depending on the load level and the type of concrete infilling.

The cases filled with HSC present a higher FCCR than the cases of NSC. Although it seemed that increasing the strength of the concrete was not of great interest because a limited FRR was obtained, a comparison with the hollow section means that using HSC is still of interest (for the limited cases analyzed) since it allows to increase the axial load sustained by the column and obtain a moderate FRR.

The cases of steel fiber reinforced concrete in the tested slender columns were not of a great utility compared with those filled with plain concrete, resulting in some cases unfavorable due to the reduction in the humidity. However, using reinforcing bars seems to be the most effective solution in some cases to avoid the need of external fire protection when designing HSS structures. In some cases, introducing bar-reinforced concrete allows the column to resist a higher axial load, which was not almost attainable by the steel tube alone, see cases RC159-6-3-80-0-40 and RC159-6-3-30-0-60 in Table 4.

\section{CONCLUSIONS}

In this paper, a series of 16 fire tests on concrete-filled tubular slender columns filled with different types of concrete was presented. The experiments focused on normal and high strength concrete, slender columns and different types of concrete reinforcement (reinforcing bars and steel fibres). A realistic three-dimensional numerical model for predicting the fire response of axially loaded CFT columns was validated against this series of fire tests. It was 
proved that a sequentially-coupled thermo-mechanical analysis instead of a fully-coupled thermo-mechanical analysis can be performed numerically without producing large errors.

The numerical model showed good agreement with the tests for the normal strength concrete filled specimens both quantitative, producing acceptable results in fire resistance rating, and qualitative, capturing the overall axial displacement response along time. By means of the validated numerical model, a deeper study of the failure mechanism of the columns was performed.

From the results of this study, it can be concluded that in slender HSS columns filled with HSC, the spalling does not appear, probably due to the reduced length of the fire tests and the reduced size of the section, which does not generate high enough pore pressures inside the concrete as to produce such phenomenon.

The utilization of reinforcing bars was found more useful for HSC than for NSC, because maintaining the same FRR the axial load applied can be increased.

If second order effects produced by the curvature in the steel tube are very large, they cannot be transferred to a fragile material as unreinforced concrete and thus the existence of concrete results of no utility in very slender elements.

This study evidences some limitations in the EC4 simple calculation model when predicting the axial buckling load of slender concrete filled hollow steel sections at elevated temperatures, for both NSC and HSC, and suggests that the model should be revised in the future on the bases of these findings.

A higher fire concrete contribution ratio was observed in the cases of HSC compared with NSC, what means that although lower values of FRR were expected for HSC given its higher probability of experiencing spalling, it is still of interest compared to using an empty hollow section, since it allows to increase the axial load level obtaining a moderate FRR. 
Nevertheless, the addition of steel fibers was not found of great utility compared with the results of plain concrete filled columns, resulting in some cases unfavorable.

\section{ACKNOWLEDGEMENTS}

The authors wish to express their sincere gratitude to the Spanish Ministry of Science and Innovation for help provided through project BIA 2009_09411, and to the European Community for the FEDER funds.

\section{REFERENCES}

[1] Twilt L, Hass R, Klingsch W, Edwards M, Dutta D. Design guide for structural hollow section columns exposed to fire. Cologne, Germany: Comité International pour le Développement et l'Etude de la Construction Tubulaire (CIDECT); 1996.

[2] Wang Y, Kodur V. 2000. Research toward use of unprotected steel structures. Journal of structural engineering 126(12):1442-1450.

[3] Portolés J.M., Romero M.L., Bonet J.L. and Filippou F.C., Experimental study of high strength concrete-filled circular tubular columns under eccentric loading, Journal of Constructional Steel Research 2011; 67:623-633.

[4] Portolés J.M., Romero M.L., Filippou F.C., Bonet J.L., Simulation and design recommendations of eccentrically loaded slender concrete-filled tubular columns, Engineering Structures 2011; 33:1576-1593.

[5] Lu H, Zhao X, Han L. Fire behaviour of high strength self-consolidating concrete filled steel tubular stub columns. Journal of constructional steel research $2009 ; 65(10-$ 11):1995-2010.

[6] Ding J, Wang YC. Realistic modelling of thermal and structural behaviour of unprotected concrete filled tubular columns in fire. Journal of Constructional Steel Research 2008; 64:1086-1102. 
[7] Espinos A, Romero M, Hospitaler A. Advanced model for predicting the fire response of concrete filled tubular columns. Journal of constructional steel research 2010; 66(89):1030-1046.

[8] V.K.R. Kodur, J.C. Latour, Experimental studies on the fire resistance of hollow steel columns filled with high-strength concrete, Institute for Research in Construction, National Research Council of Canada (NRCC), Ottawa, Canada, 2005.

[9] Ali F, Nadjai A, Choi S. Numerical and experimental investigation of the behavior of high strength concrete columns in fire. Engineering structures 2010; 32(5):1236-1243.

[10] Schaumann P, Kodur V, Bahr O. Fire behaviour of hollow structural section steel columns filled with high strength concrete. Journal of constructional steel research 2009; 65(8-9):1794-1802.

[11] Lie TT, Chabot M. Experimental studies on the fire resistance of hollow steel columns filled with plain concrete. Internal report No. 611. Ottawa, Canada: Institute for Research in Construction, National Research Council of Canada (NRCC); 1992.

[12] Chabot M, Lie TT. Experimental studies on the fire resistance of hollow steel columns filled with bar-reinforced concrete. Internal report No. 628. Ottawa, Canada: Institute for Research in Construction, National Research Council of Canada (NRCC); 1992.

[13] Lie TT. Fire resistance of circular steel columns filled with bar-reinforced concrete. Journal of Structural Engineering-ASCE 1994; 120(5):1489-1509.

[14] Kordina K, Klingsch W. Fire resistance of composite columns of concrete filled hollow sections. CIDECT Research Project 15C1/C2-83/27. Cologne, Germany: Comité International pour le Développement et l'Etude de la Construction Tubulaire; 1983.

[15] Park S, Choi S, Chung K. A Study on the fire-resistance of concrete-filled steel square tube columns without fire protection under constant central axial loads. Steel And Composite Structures 2008; 8(6):491-510. 
[16] Park S, Chung K, Choi S. 2007. A study on failure prediction and design equation of concrete filled square steel tube columns under fire condition. International Journal of Steel Structures 7(3):183-191.

[17] Chung K, Park S, Choi S. Fire Resistance of Concrete Filled Square Steel Tube Columns Subjected to Eccentric Axial Load. International Journal of Steel Structures 2009; 9(1):69-76.

[18] Han L, Yang Y, Xu L. An experimental study and calculation on the fire resistance of concrete-filled SHS and RHS columns. Journal of constructional steel research 2003; 59(4):427-452.

[19] ISO 834: Fire resistance tests, elements of building construction. Switzerland: International Standards Organisation; 1980.

[20] Hass R, Ameler J, Zies H. Fire Resistance of Hollow Section Composite Columns with High Strength Concrete Filling, CIDECT Research Project 15P-12/00, Brunswick, Germany: Comité International pour le Développement et l'Etude de la Construction Tubulaire; 2000.

[21] Han L, Zhao X, Yang Y, Feng J. Experimental study and calculation of fire resistance of concrete-filled hollow steel columns. Journal of structural engineering 2003; 129(3):346-356.

[22] C. Lacuesta, M.L. Romero, S. Ivorra, J.M. Portoles, "A Three-Dimensional Numerical Model of Circular Concrete Filled Columns", in B.H.V. Topping, G. Montero, R. Montenegro, (Editors), "Proceedings of the Eighth International Conference on Computational Structures Technology", Civil-Comp Press, Stirlingshire, UK, Paper 22, 2006. doi:10.4203/ccp.83.22.

[23] Aribert JM, Renaud C, Zhao B. Simplified fire design for composite hollow-section columns. Structures \& Buildings 2008; 161:325-336. 
[24] CEN. EN 1994-1-2, Eurocode 4: Design of composite steel and concrete structures. Part 1-2: General rules - Structural fire design. Brussels, Belgium: Comité Européen de Normalisation; 2005

[25] Espinos A, Gardner L, Romero M, Hospitaler A. Fire behaviour of concrete filled elliptical steel columns. Thin-walled structures 2011; 49(2):239-255.

[26] CEN. EN 1992-1-2, Eurocode 2: Design of concrete structures. Part 1-2: General rules Structural fire design. Brussels, Belgium: Comité Européen de Normalisation; 2004.

[27] ABAQUS. ABAQUS/Standard Version 6.10 User's Manual: Volumes I-III. Pawtucket, Rhode Island: Hibbit, Karlsson \& Sorenson, Inc.; 2010. 


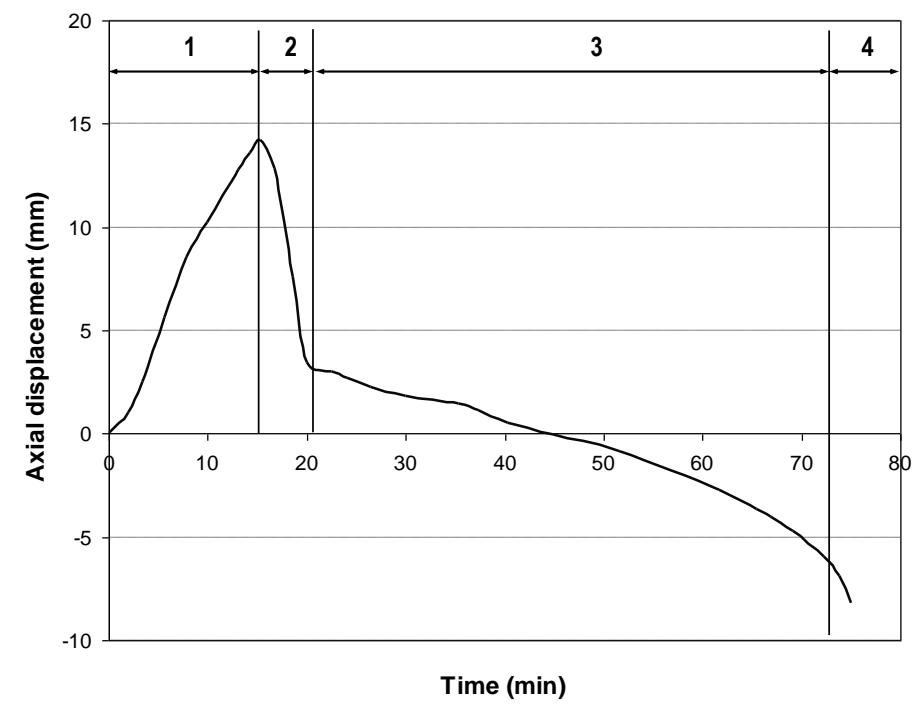

Figure 1. Axial displacement versus time, from Espinos et al [7] 


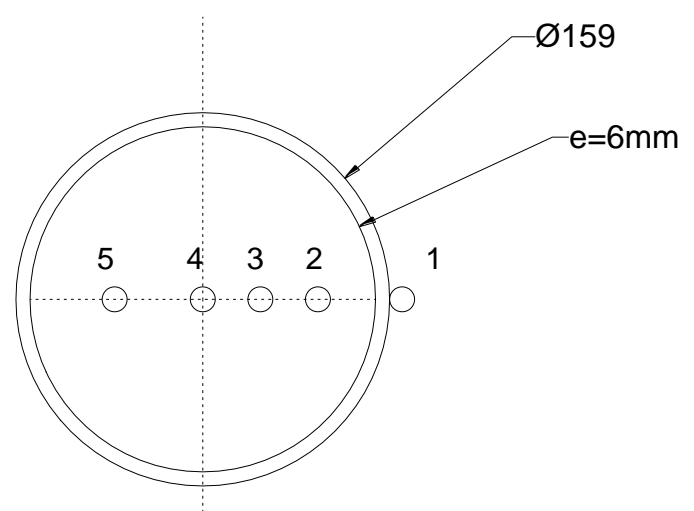

a)

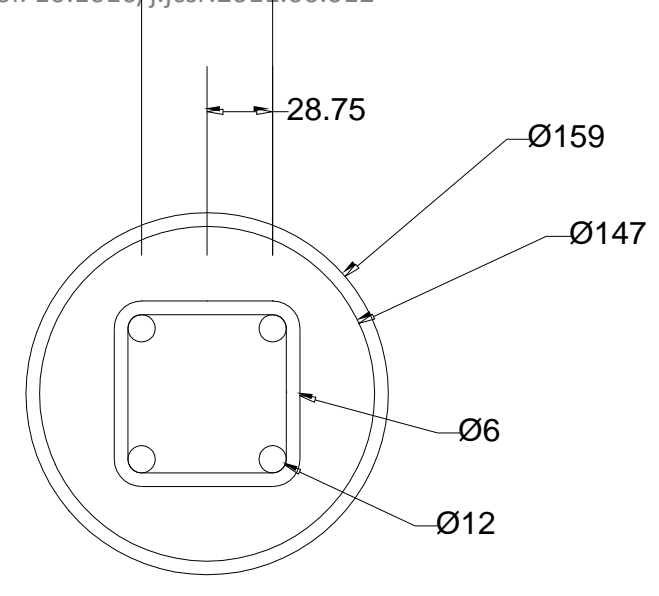

b)
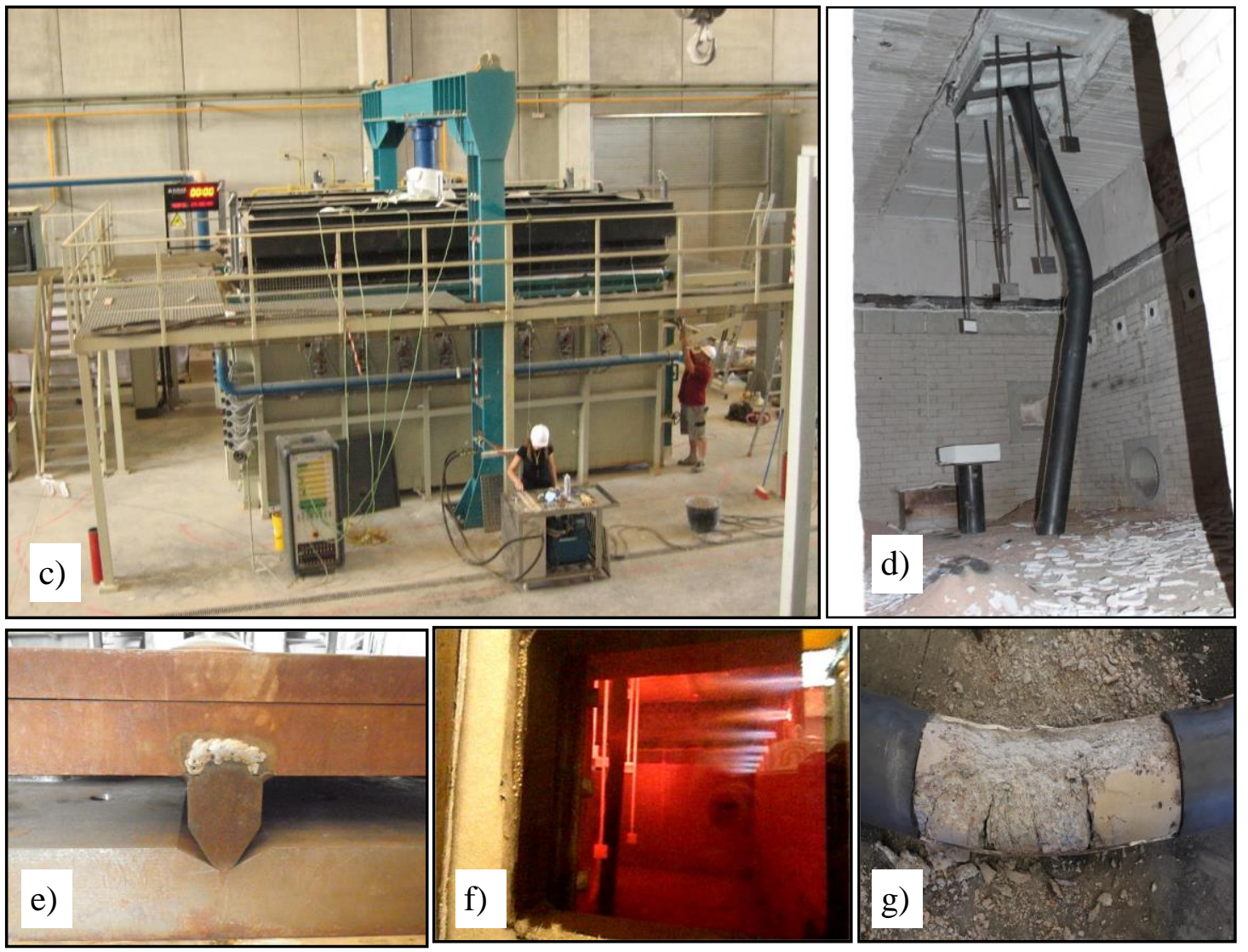

Figure 2. General view of: (a) thermocouples layout. (b) reinforcement arrangement. (c) furnace (d) column after failure e) pinned support f) burners g) concrete cracking at midsection. 

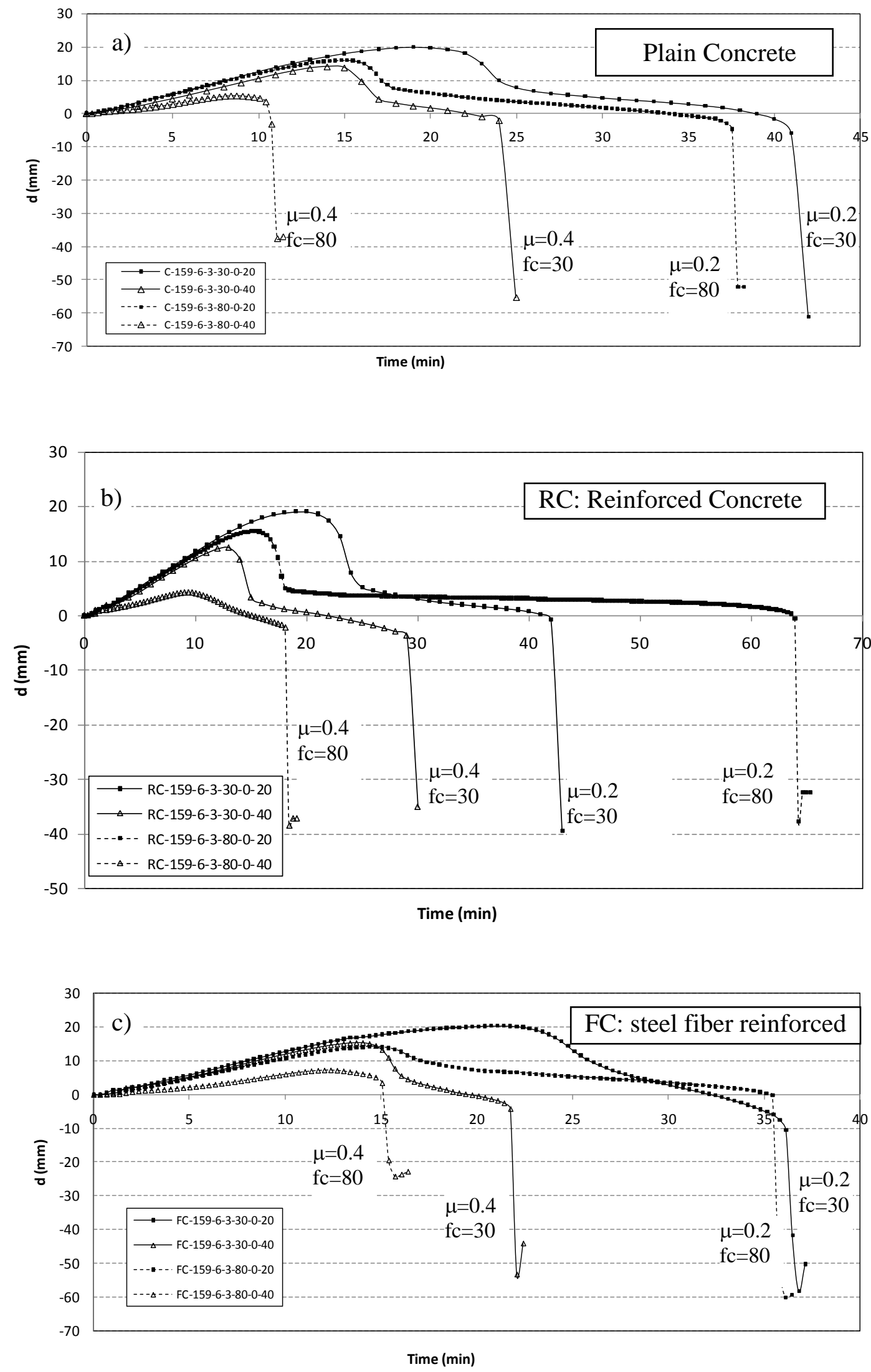

Figure 3. Concrete strength influence: a) PC b) RC c) FC 


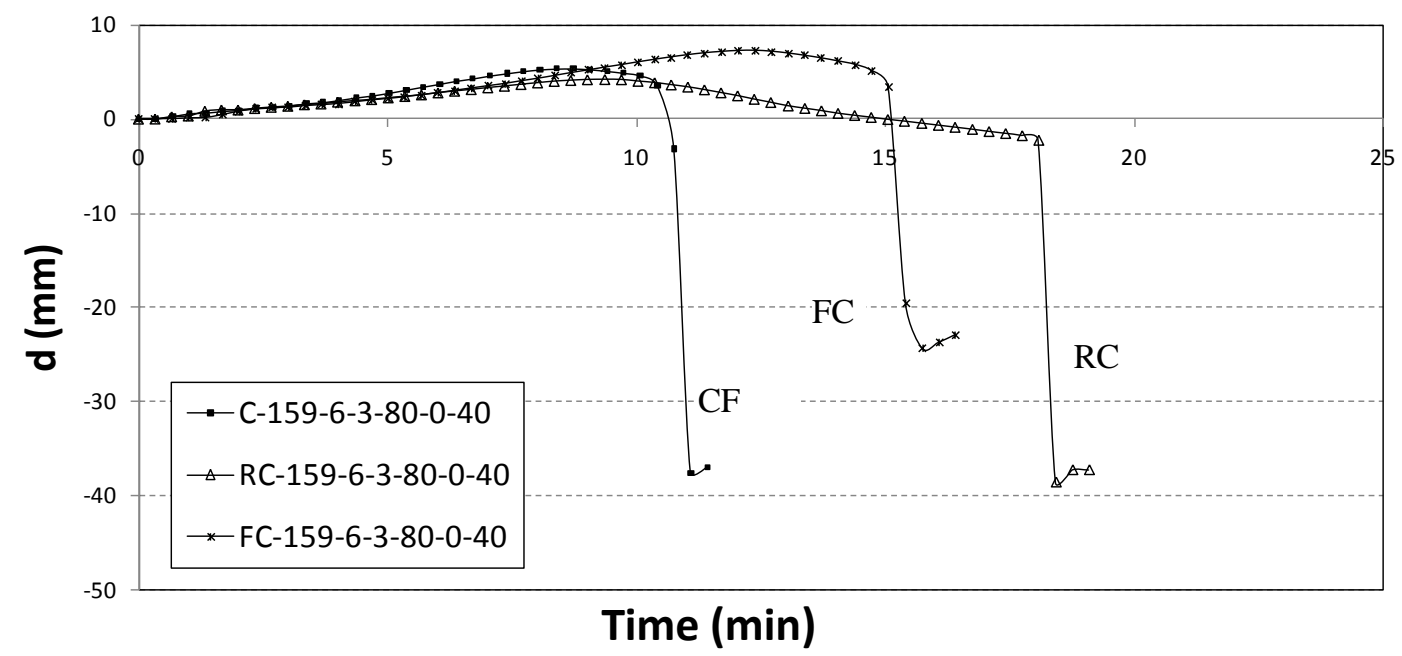

a) Type of infilling for HSC and $40 \%$ axial load ratio

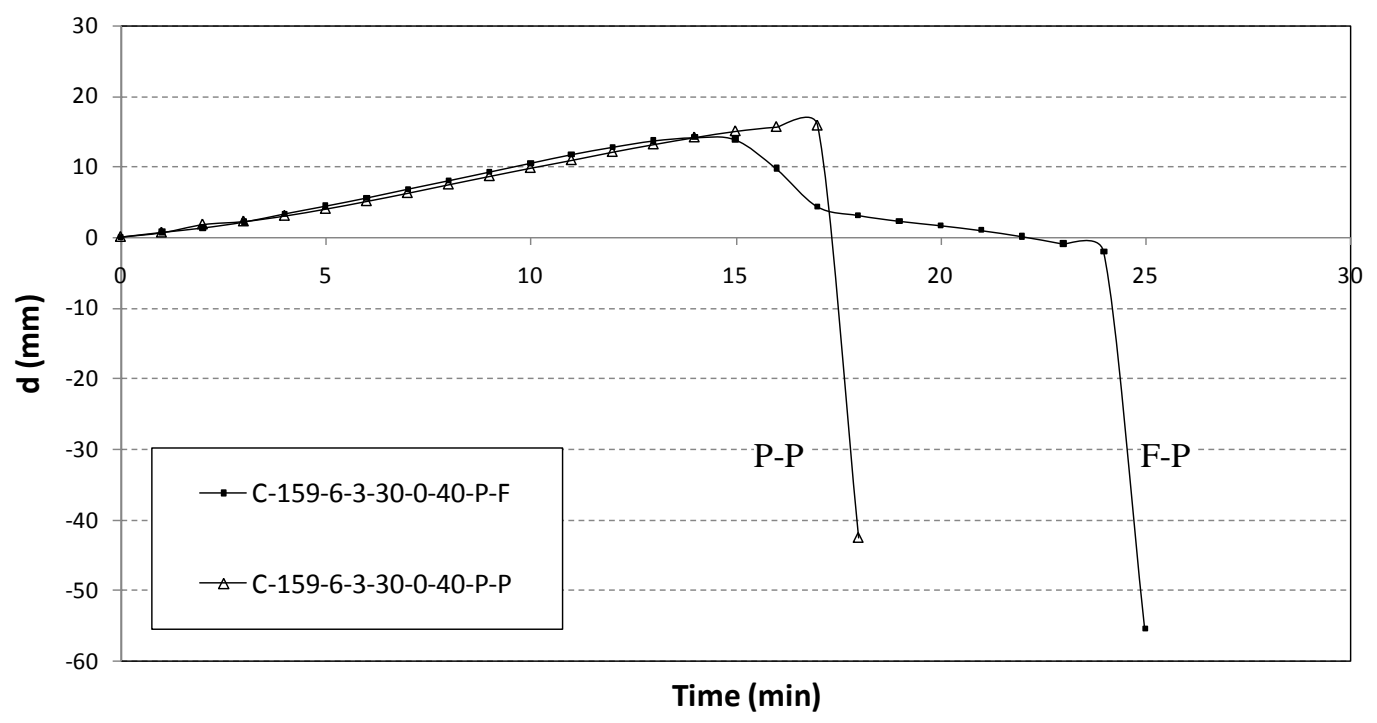

b) Influence of the slenderness for NSC and $40 \%$ axial load ratio

Figure 4. Comparison of fire resistance for different parameters. 


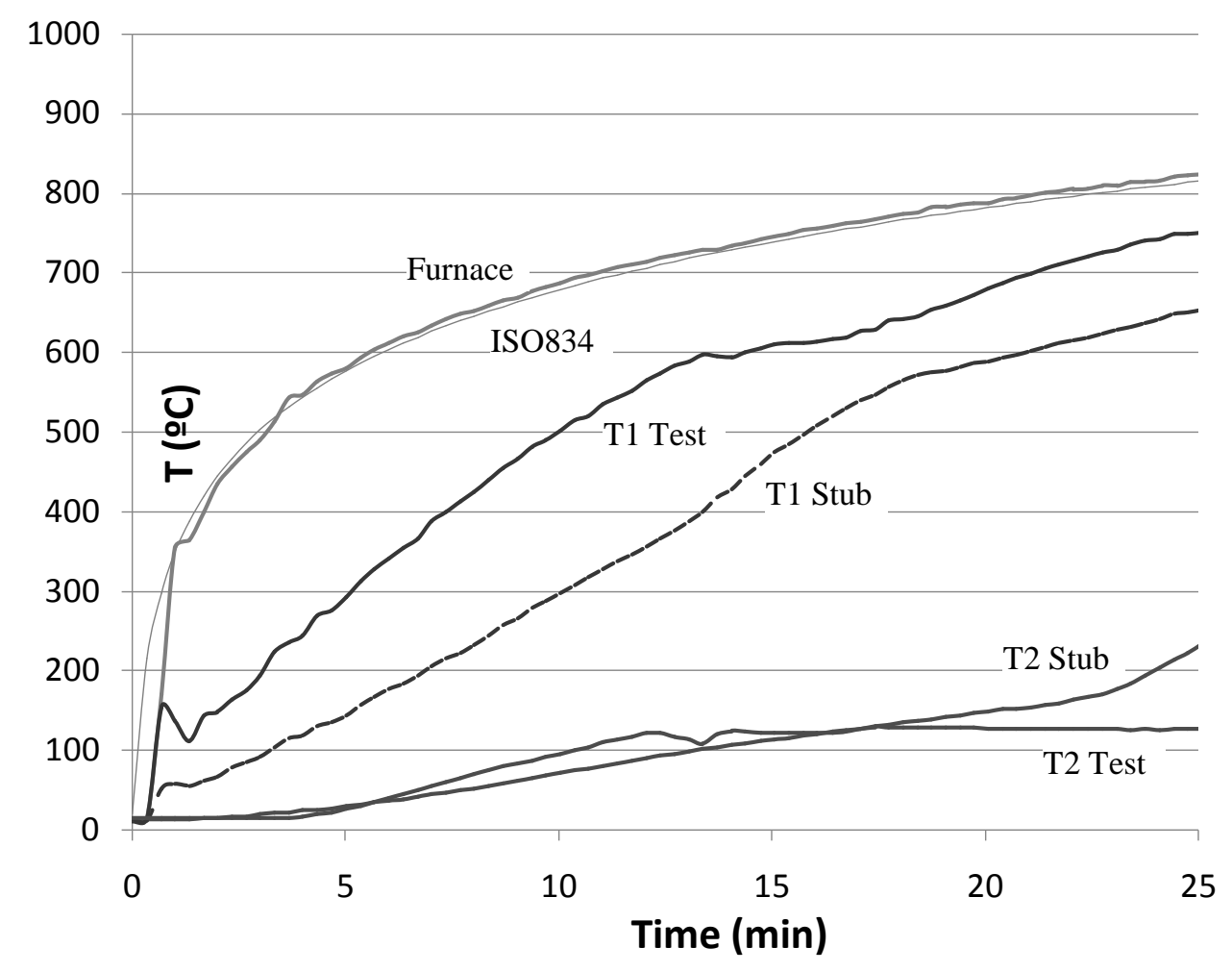

Figure 5. Comparison of temperatures between the slender and stub column, for FC159-63-30-0-20. 


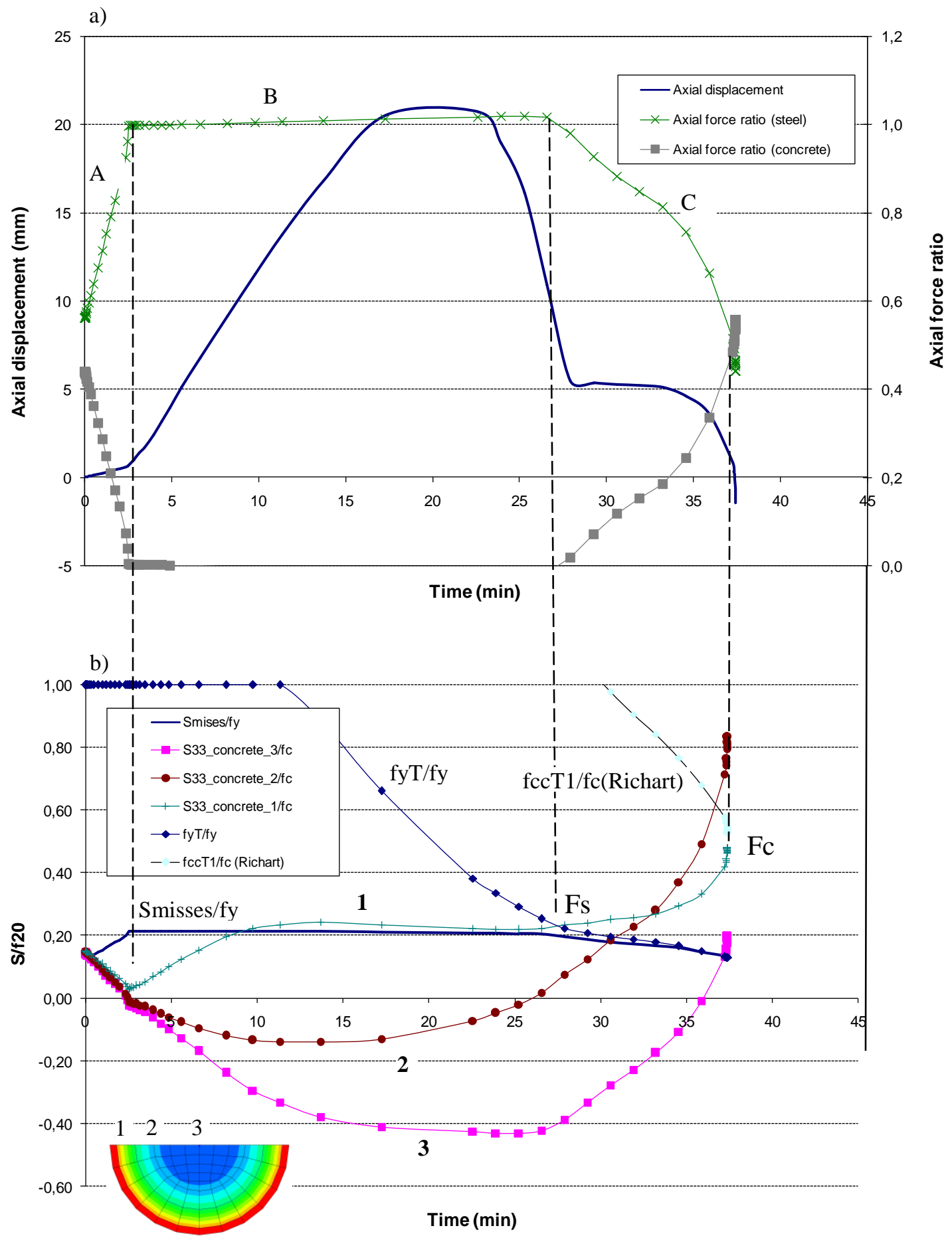

Figure 6. Distribution of forces and stresses in the failure section, for C159-6-3-30-0-20. 


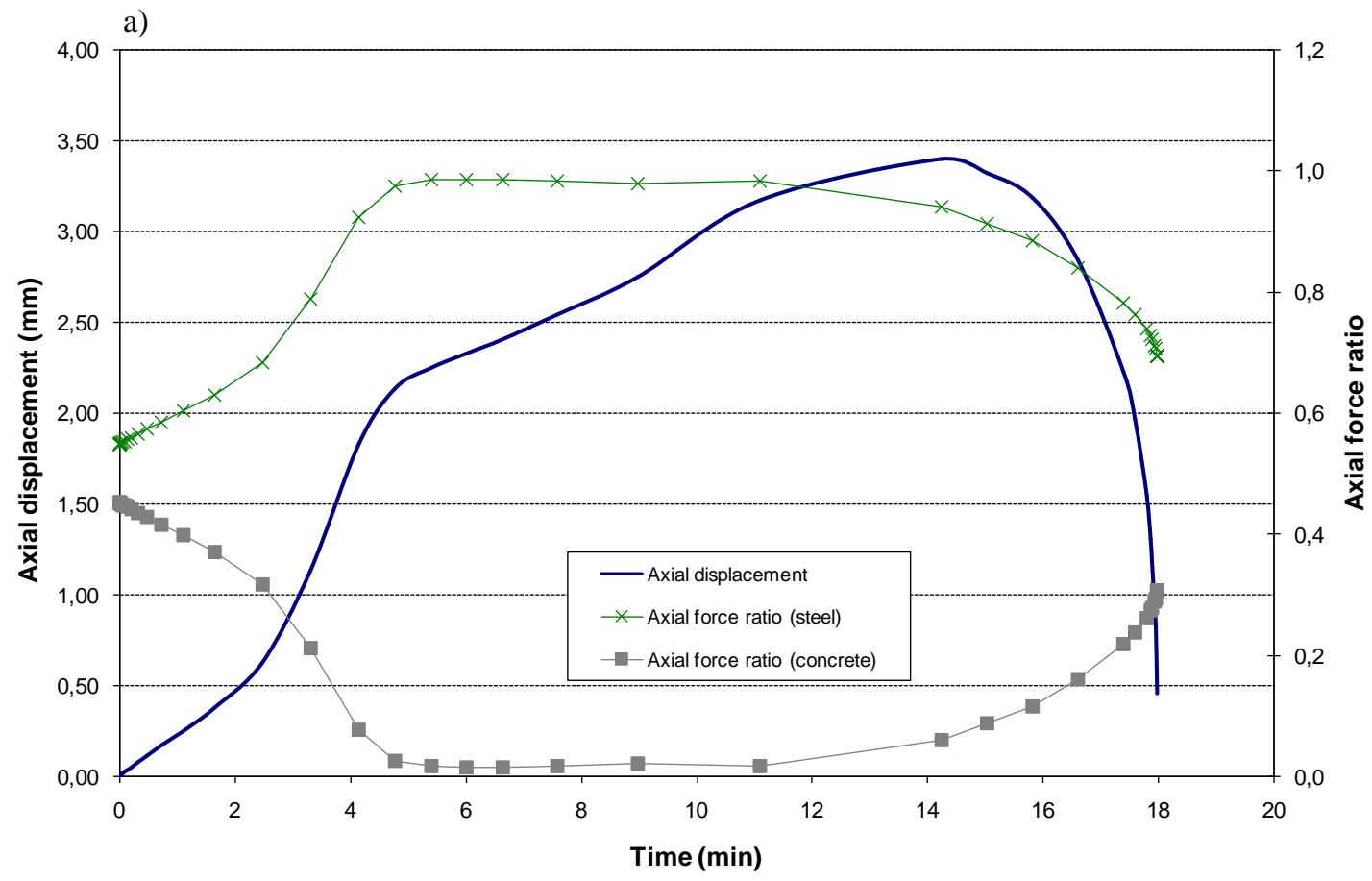

b)

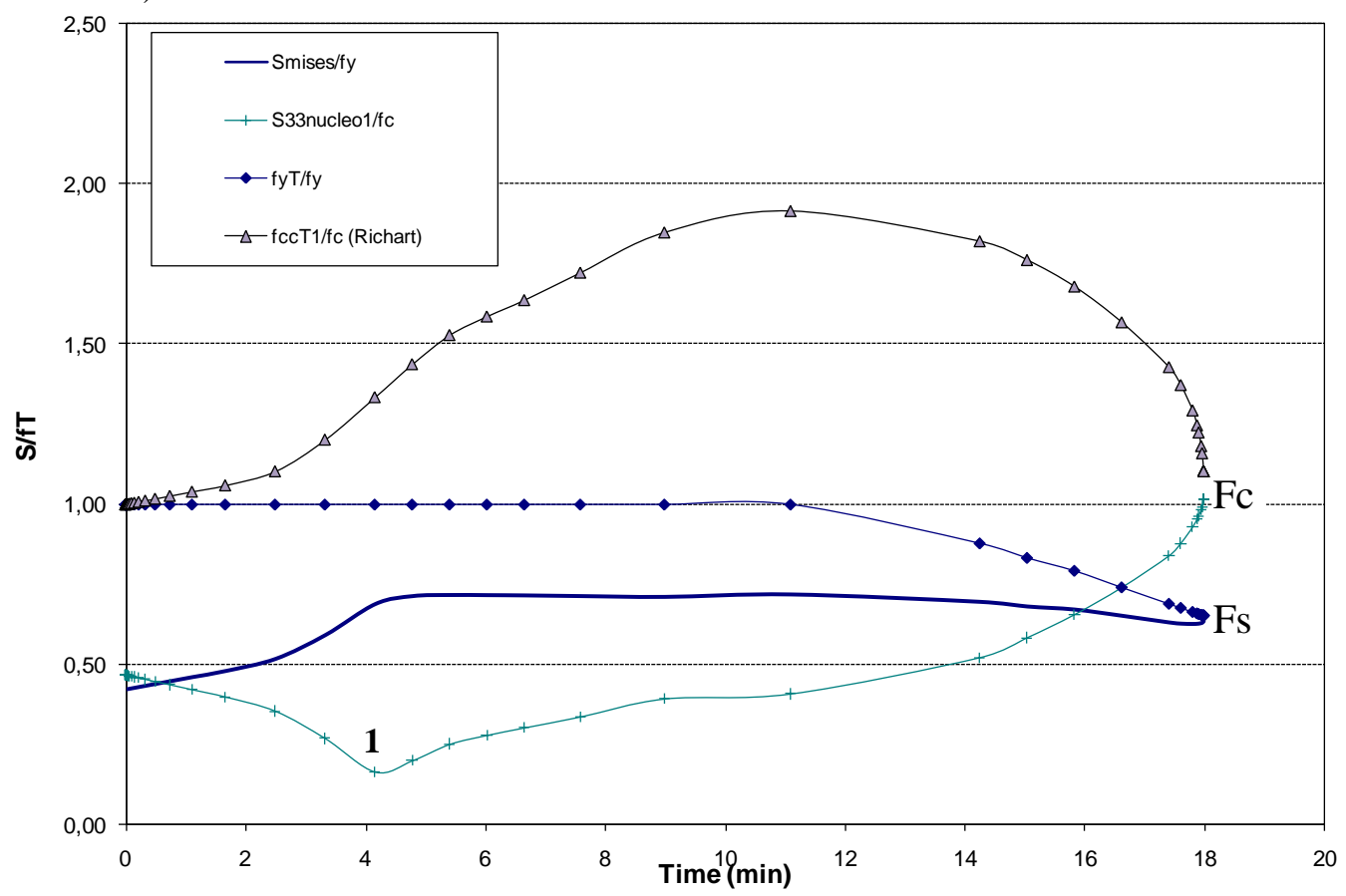

Figure 7. Distribution of forces and stresses in the failure section, for RC159-6-3-30-0-60. 
Table 1. Test properties and results

\begin{tabular}{|c|c|c|c|c|c|c|c|c|c|c|}
\hline $\mathrm{N}^{\mathrm{o}}$ & Name & $\begin{array}{c}\mathrm{D} \\
\mathrm{mm}\end{array}$ & $\underset{\mathrm{mm}}{\mathrm{t}}$ & $\begin{array}{l}\mu \\
\%\end{array}$ & $\begin{array}{c}\mathrm{fc} \\
\mathrm{MPa}\end{array}$ & $\begin{array}{c}\text { fy } \\
\mathrm{MPa}\end{array}$ & $\lambda$ & $\begin{array}{l}\text { Axial } \\
\text { Load } \\
(\mathrm{kN})\end{array}$ & B.C & $\begin{array}{c}\text { Test } \\
\text { FRR } \\
\text { min }\end{array}$ \\
\hline 1 & C159-6-3-0-0-20-P-P & 159 & 6 & 40 & - & 337.8 & 0.75 & 206 & P-P & 13 \\
\hline 2 & C159-6-3-30-0-40-P-P & 159 & 6 & 40 & 30.1 & 337.8 & 0.88 & 338 & P-P & 18 \\
\hline 3 & C159-6-3-30-0-20 & 159 & 6 & 20 & 35.75 & 337.8 & 0.61 & 198 & F-P & 42 \\
\hline 4 & C159-6-3-30-0-40 & 159 & 6 & 40 & 28.55 & 337.8 & 0.62 & 396 & F-P & 25 \\
\hline 5 & C159-6-3-30-0-60 & 159 & 6 & 60 & 34.05 & 337.8 & 0.61 & 594 & F-P & 14 \\
\hline 6 & C159-6-3-80-0-20 & 159 & 6 & 20 & 71.14 & 341.4 & 0.73 & 335 & F-P & 38 \\
\hline 7 & C159-6-3-80-0-40 & 159 & 6 & 40 & 69 & 341.4 & 0.73 & 670 & F-P & 11 \\
\hline 8 & RC159-6-3-30-0-20 & 159 & 6 & 20 & 23.9 & 337.8 & 0.66 & 229 & F-P & 43 \\
\hline 9 & RC159-6-3-30-0-40 & 159 & 6 & 40 & 30 & 337.8 & 0.65 & 458 & F-P & 30 \\
\hline 10 & RC159-6-3-30-0-60 & 159 & 6 & 60 & 33.7 & 337.8 & 0.65 & 687 & F-P & 13 \\
\hline 11 & RC159-6-3-80-0-20 & 159 & 6 & 20 & 69.03 & 337.8 & 0.75 & 343 & F-P & 65 \\
\hline 12 & RC159-6-3-80-0-40 & 159 & 6 & 40 & 77 & 337.8 & 0.75 & 720 & F-P & 19 \\
\hline 13 & FC159-6-3-30-0-20 & 159 & 6 & 20 & 28.3 & 337.8 & 0.62 & 198 & F-P & 37 \\
\hline 14 & FC159-6-3-30-0-40 & 159 & 6 & 40 & 26.7 & 334.4 & 0.62 & 396 & F-P & 22 \\
\hline 15 & FC159-6-3-80-0-20 & 159 & 6 & 20 & 93.62 & 337.8 & 0.70 & 335 & F-P & 36 \\
\hline 16 & FC159-6-3-80-0-40 & 159 & 6 & 40 & 90.16 & 334.4 & 0.71 & 670 & F-P & 16 \\
\hline
\end{tabular}

where $\mathrm{C}$ stands for plain concrete, $\mathrm{RC}$ for reinforced concrete and $\mathrm{FC}$ for steel fiber reinforced concrete; and $\mu$ is the axial load level. $\mathrm{P}-\mathrm{P}=$ pinned-pinned and F-P $=$ fixed-pinned end conditions 
Table 2. Comparison of tests, Euro Code 4 and Numerical model.

\begin{tabular}{|c|c|c|c|c|c|c|}
\hline \multicolumn{7}{|c|}{ NORMAL STRENGTH CONCRETE } \\
\hline & \multicolumn{3}{|c|}{$\begin{array}{c}\text { Axial Force } \\
(\mathbf{k N})\end{array}$} & \multicolumn{3}{|c|}{$\begin{array}{l}\text { FRR } \\
(\min )\end{array}$} \\
\hline Column specimen & TEST & EC4-1-2 & TEST/EC4 & TEST & NUM & TEST/NUM \\
\hline C159-6-3-30-0-20 & 198 & 250,4 & 0,79 & 25 & 20 & 1,25 \\
\hline C159-6-3-30-0-40 & 396 & 482,5 & 0,82 & 42 & 37 & 1,14 \\
\hline C159-6-3-30-0-60 & 594 & 706,5 & 0,84 & 14 & 16 & 0,88 \\
\hline RC159-6-3-30-0-20 & 229 & 344,4 & 0,66 & 43 & 38 & 1,13 \\
\hline RC159-6-3-30-0-40 & 458 & 382,7 & 1,20 & 30 & 24 & 1,25 \\
\hline RC159-6-3-30-0-60 & 687 & 1129 & 0,61 & 13 & 17 & 0,76 \\
\hline FC159-6-3-30-0-20 & 198 & 263,4 & 0,75 & 36 & 31 & 1,16 \\
\hline \multirow[t]{3}{*}{ FC159-6-3-30-0-40 } & 396 & 355,2 & 1,11 & 22 & 19 & 1,16 \\
\hline & & MEAN & 0,85 & & & 1,09 \\
\hline & STL & DEV. & 0,20 & & & 0,16 \\
\hline
\end{tabular}

\begin{tabular}{|c|c|c|c|c|c|c|}
\hline \multicolumn{7}{|c|}{ HIGH STRENGTH CONCRETE } \\
\hline & \multicolumn{3}{|c|}{$\begin{array}{c}\text { Axial Force } \\
(\mathbf{k N})\end{array}$} & \multicolumn{3}{|c|}{$\begin{array}{l}\text { FRR } \\
(\text { min })\end{array}$} \\
\hline Column specimen & TEST & EC4-1-2 & TEST/EC4 & TEST & NUM & TEST/NUM \\
\hline C159-6-3-80-0-20 & 335 & 348,1 & 0,96 & 37 & 31 & 1,19 \\
\hline C159-6-3-80-0-40 & 670 & 1104,8 & 0,61 & 11 & 18 & 0,61 \\
\hline RC159-6-3-80-0-20 & 343 & 339,6 & 1,01 & 64 & 35 & 1,83 \\
\hline RC159-6-3-80-0-40 & 720 & 711 & 1,01 & 18 & 20 & 0,90 \\
\hline FC159-6-3-80-0-20 & 335 & 435,7 & 0,77 & 35 & 40 & 0,88 \\
\hline \multirow[t]{3}{*}{ FC159-6-3-80-0-40 } & 670 & 668,1 & 1,00 & 15 & 22 & 0,68 \\
\hline & & MEAN & 0,89 & & & 1,02 \\
\hline & & STD. DEV. & 0,17 & & & 0,45 \\
\hline
\end{tabular}


Table 3. Critical Temperature

\begin{tabular}{lccccccc}
\hline & & $\mu$ & \multicolumn{2}{c}{ Tcr test $\left({ }^{\circ} \mathbf{C}\right)$} & \multicolumn{2}{c}{ Tcr code $\left({ }^{\circ} \mathbf{C}\right)$} \\
\hline & nom & real & hollow & CFT & hollow & nom & real \\
\hline C159-6-3-30-0-20 & 0,2 & 0,14 & 0,22 & 850 & 716,0 & 728,7 & 785,2 \\
\hline C159-6-3-30-0-40 & 0,4 & 0,29 & 0,44 & 654 & 610,5 & 623,6 & 670,1 \\
\hline C159-6-3-30-0-60 & 0,6 & 0,42 & 0,65 & 583 & 543,7 & 558,5 & 616,5 \\
\hline \multicolumn{1}{c}{} & & & & & & \\
\hline C159-6-3-80-0-20 & 0,2 & 0,18 & 0,37 & 756 & 636,3 & 728,7 & 743,3 \\
\hline C159-6-3-80-0-40 & 0,4 & 0,37 & 0,74 & 424 & 520,5 & 623,6 & 636,8 \\
\hline & & & & & & & \\
\hline RC159-6-3-30-0-20 & 0,2 & 0,16 & 0,25 & 768 & 694,1 & 728,7 & 759,9 \\
\hline RC159-6-3-30-0-40 & 0,4 & 0,31 & 0,50 & 726 & 587,5 & 623,6 & 664,5 \\
\hline RC159-6-3-30-0-60 & 0,6 & 0,44 & 0,75 & 444 & 515,2 & 558,5 & 607,9 \\
\hline & & & & & & & \\
\hline RC159-6-3-80-0-20 & 0,2 & 0,18 & 0,38 & 913 & 632,7 & 728,7 & 748,7 \\
\hline RC159-6-3-80-0-40 & 0,4 & 0,35 & 0,79 & 496 & 504,7 & 623,6 & 642,5 \\
\hline & & & & & & & \\
\hline FC159-6-3-30-0-20 & 0,2 & 0,15 & 0,22 & 751 & 716,0 & 728,7 & 774,2 \\
\hline FC159-6-3-30-0-40 & 0,4 & 0,30 & 0,44 & 707 & 610,5 & 623,6 & 665,3 \\
\hline & & & & & & \\
\hline FC159-6-3-80-0-20 & 0,2 & 0,16 & 0,37 & 763 & 636,3 & 728,7 & 757,8 \\
\hline FC159-6-3-80-0-40 & 0,4 & 0,34 & 0,74 & 481 & 520,5 & 623,6 & 649,8 \\
\hline
\end{tabular}


Table 4. Fire Concrete Contribution Ratio (FCCR)

\begin{tabular}{ccccc}
\hline NAME & Load level CFT (TEST) & HOLLOW & FCCR \\
\hline C159-6-3-30-0-40-P-P & 0,4 & 18 & 9 & 2,00 \\
\hline & & & & \\
\hline C159-6-3-30-0-20 & 0,2 & 42 & 14 & 3,00 \\
\hline C159-6-3-30-0-40 & 0,4 & 25 & 10 & 2,50 \\
\hline C159-6-3-30-0-60 & 0,6 & 14 & 5 & 2,80 \\
\hline C159-6-3-80-0-20 & 0,2 & 38 & 11 & 3,45 \\
\hline C159-6-3-80-0-40 & 0,4 & 11 & 3 & 3,67 \\
\hline & & & & \\
\hline RC159-6-3-30-0-20 & 0,2 & 43 & 13 & 3,31 \\
\hline RC159-6-3-30-0-40 & 0,4 & 30 & 9 & 3,33 \\
\hline RC159-6-3-30-0-60 & 0,6 & 13 & 4 & 3,25 \\
\hline RC159-6-3-80-0-20 & 0,2 & 65 & 11 & 5,91 \\
\hline RC159-6-3-80-0-40 & 0,4 & 19 & 4 & 4,75 \\
\hline & & & & \\
\hline FC159-6-3-30-0-20 & 0,2 & 36 & 14 & 2,57 \\
\hline FC159-6-3-30-0-40 & 0,4 & 22 & 10 & 2,20 \\
\hline FC159-6-3-80-0-20 & 0,2 & 36 & 11 & 3,27 \\
\hline FC159-6-3-80-0-40 & 0,4 & 16 & 3 & 5,33 \\
\hline
\end{tabular}

